\title{
ENTREVISTA
}

\section{EI tratamiento de la Masonería en los periódicos mexicanos Diario del Hogar, El Partido Liberal y El Tiempo, durante 1895/1896}

El investigador Julio Martínez García ha defendido su Tesis de Maestría, cuyo título es "El tratamiento de la Masonería en los periódicos mexicanos Diario del Hogar, El Partido Liberal y El Tiempo, durante 1895/1896" en la Universidad Nacional de Educación a Distancia (UNED) en España en septiembre de 2015. Julio Martínez García nació en 1985 en Guadalajara, España.

El autor nos ha concedido la siguiente entrevista.

¿Cuáles fueron los motivos que le llevó a enfocar su investigación hacia la Masonería?

La Masonería siempre ha sido un movimiento que me ha interesado. Desde que tengo uso de razón las logias me resultaron llamativas, tanto desde su perspectiva de sociabilidad política como por los discursos que se han construido sobre ella. Precisamente, la Fraternidad, a lo largo de la historia, ha sido el epicentro de un debate muy enconado. En torno a ella se han construido imaginarios irreconciliables, definidos por ensalzar a la organización o intentar censurarla y acabar con ella.

Estas posturas -a veces muy polarizadas- me hicieron querer saber más sobre la mencionada realidad. De esta forma, me puse a leer sobre la misma, encontrándome una entidad que, como el propio ser humano, tiene sus virtudes y sus defectos. En definitiva, tras algunas lecturas, se ha convertido en una entidad que me ha acabado atrapando.

Por ello, en la tesis he querido combinar varias de mis pasiones. Por un lado, el periodismo, una vocación que tengo desde hace años. De esta forma, no dudé en estudiar la imagen de la Orden en los medios de comunicación. Además, los periódicos (y la prensa en todos sus formatos) se han instituido, tradicionalmente, como una de las mejores formas de conocer e investigar la historia, porque en ellos se han expresado diversos posicionamientos políticos, sociales y económicos. Pero no sólo eso. Como señala María Eugenia Vázquez sobre las publicaciones, "su elaboración y consumo es una parte fundamental de los procesos históricos, por lo que deben ser estudiadas en sí mismas"1 (Vázquez, 2008: 379).

\footnotetext{
${ }^{1}$ María Eugenia Vázquez, La formación de una cultura política republicana. El debate público sobre la Masonería en México 1821-1830. (Tesis de doctoral en Historia, El Colegio de Michoacán, 2008), 379.
} 
Del mismo modo, otra de mis querencias que he atender e integrar en la tesis ha sido la de la historia. Por ello, la investigación que presenté el pasado septiembre de 2015 en la UNED se centró en el Porfiriato mexicano. Y más concretamente, en el periodo comprendido entre el 1 de julio de 1895 y el 31 de mayo de 1896. En este sentido, investigar, conocer y divulgar el pasado es fundamental para poder afrontar el presente y tener la posibilidad de edificar un futuro mejor para todos.

Asimismo, y para terminar esta pregunta, no puedo dejar de lado la que se ha convertido en otra de mis pasiones: México. Al proceder de Guadalajara (España), hay vínculos de hermanamiento con la segunda ciudad mexicana más populosa. Y, por tanto, siempre hubo relaciones culturales entre las dos localidades: la española y la jalisciense. De esta forma, mi interés por el mencionado país americano comenzó desde hace tiempo. Una pasión que se confirmó -y se incrementó- en 2013 y 2014, cuando estuve viviendo en Puebla.

Y si a eso se añade que la historia de la Masonería y de los medios de comunicación en México es muy variada e interesante, ¿qué más puedo pedir?

¿Cuáles fueron las fuentes que ha utilizado?

Básicamente he analizado los ejemplares de los tres periódicos seleccionados para la investigación, que fueron Diario del Hogar, El Partido del Hogar y El Tiempo. He consultado los ejemplares de estas cabeceras publicados entre el 1 de julio de 1895 y el 31 de mayo de 1896. Además, también he incluido textos del Boletín Masónico. Órgano Oficial de la Gran Dieta Simbólica de los Estados Unidos Mexicanos, como la carta de dimisión de Porfirio Díaz de la Gran Dieta Simbólica. En la búsqueda de estos documentos recibí la ayuda del historiador Carlos Francisco Martínez Moreno. En último lugar, he repasado bibliografía para poder construir el marco teórico y el contexto histórico del trabajo.

¿Cuáles fueron las principales dificultades con las que se ha encontrado? ¿Cómo las ha superado?

En relación a las dificultades durante mi tesis, debo decir que encontré pocas. Los periódicos consultados, por regla general, se encuentran en buen estado y su acervo está bastante completo. Además, la Hemeroteca Nacional de México está realizando un trabajo muy importante de digitalización de sus fondos, por lo que se han facilitado mucho las consultas. Al mismo tiempo, en cuanto a la bibliografía, la historia de la Masonería mexicana está siendo estudiada por especialistas de primer nivel, que han escrito obras de 
una gran calidad. Gracias a su labor, el trabajo de consulta bibliográfica ha sido muy gratificante. Y, por último, para el desempeño dentro del archivo recibí ayuda de expertos que, como Carlos Francisco Martínez, me orientaron al respecto.

¿Cuáles fueron las principales problemáticas históricas que su trabajo ha resuelto?

Principalmente, lo que he podido comprobar es que los diferentes medios de comunicación trataban a la Masonería de acuerdo a su línea editorial previa. Si era una publicación católica, como El Tiempo, se mostraba una gran obsesión en torno a la Masonería, asumiendo en muchas ocasiones los postulados del Vaticano al respecto. $\mathrm{Si}$, como ocurría con El Partido Liberal, se trataba de una cabecera liberal/oficialista, se subordinaba la Fraternidad a la figura del presidente. Según fuera la relación de Porfirio Díaz con la Orden, así se trataba a la mencionada organización. Y, en último lugar, en el caso de Diario del Hogar, al tratarse de un rotativo liberal cuyo director estaba iniciado, se abordó la Hermandad desde una perspectiva positiva. En consecuencia, la imagen que se dibujaba de la Cofradía atendía a la ideología de cada medio.

¿Por favor, podría resumir la esencia de su Tesis en dos líneas?

A través del enfoque de la historia de la prensa he querido estudiar los imaginarios que, en torno a la Masonería, se han incluido en tres de los medios más destacados del México de finales del siglo XIX. Además, al tratarse de una triada de periódicos de diferentes ideologías (uno oposicionista católico; otro oposicionista liberal; y un tercero, oficialista liberal), se han podido observar las diferencias y similitudes del tratamiento de la Orden en cada uno de ellos.

¿Cuáles fueron las lecciones, a todos los niveles, personal y profesional, que usted ha deducido de su experiencia investigativa?

Las enseñanzas han sido muchas. La principal ha consistido en que la presente tesis me ha animado a seguir investigando sobre un tema que me apasiona, que es el de la Masonería en México y su reflejo en los medios de comunicación. Además, gracias a la labor realizada, me he dado cuenta que el trabajo académico, aunque en algunas ocasiones pueda ser algo solitario, siempre da sus frutos. Hay que tener paciencia y constancia, porque en todos los casos se llegará a un destino. Y, sobre todo, durante mi labor, he tenido la oportunidad de entrar en contacto con gente estupenda que estudia lo mismo que yo y con la que he podido intercambiar enfoques y perspectivas. En definitiva, me he enriquecido como persona. 
¿Ahora, cuáles son sus proyectos profesionales?

A partir de ahora seguiré haciendo investigaciones y formándome. De hecho, estoy viendo la posibilidad de continuar el trabajo emprendido a través de un programa doctoral. Al mismo tiempo, durante los primeros meses de 2016, intentaré insertarme en el mundo laboral. Para ello, buscaré suerte en América Latina, más concretamente en México.

¿Quisiera destacar algún aspecto que no se ha contemplado y que usted consideraría digno de reseñar?

Deseo reconocer la labor, paciencia y dedicación que ha tenido conmigo Juan José Morales Ruiz, mi tutor de la UNED durante la tesis de maestría. Ha sido estupendo el poder encontrarme con él y que me aceptase como alumno, a pesar de que en ocasiones he podido llegar a ser un poco insistente en algunas dudas. Por ello, quiero expresarle mi agradecimiento por toda la ayuda que me ha prestado.

Asimismo, quiero mencionar a algunos de los investigadores de la historia de la Masonería en México que también me han ayudado en mis investigaciones. Una colaboración que me ha permitido encontrar documentación, consultar nueva bibliografía y observar perspectivas y enfoques novedosos. Entre ellos, debo mencionar a Guillermo de los Reyes, María Eugenia Vázquez, Carlos Francisco Martínez o Marco Antonio Flores. Muchas gracias a todos ellos.

Esta entrevista se efectúo de forma telemática el 3 de octubre de 2015.

Autores de la entrevista: Ricardo Martínez Esquivel e Yván Pozuelo Andrés, Director y Editor de REHMLAC+.

DOI: http://dx.doi.org/10.15517/rehmlac.v7i2.22765 